\title{
A 2-year-old Girl with Diphyllobothrium nihonkaiense Infection Treated with Oral Praziquantel and a Laxative
}

\author{
Atsushi Fujita, Makoto Migita, Takahiro Ueda and Yoshitaka Fukunaga \\ Department of Pediatrics, Graduate School of Medicine, Nippon Medical School
}

\begin{abstract}
We report a case of Diphyllobothrium nihonkaiense infection in a 2-year-old Japanese girl. When infection occurs in early childhood, it is necessary to offer supportive care in addition to standard treatment with oral praziquantel or with of a duodenal tube using a radiopaque contrast medium. We treated $D$. nihonkaiense infection in a 2-year-old girl successfully treated with oral praziquantel and a laxative.
\end{abstract}

(J Nippon Med Sch 2008; 75: 225-227)

Key words: Diphyllobothrium nihonkaiense, child case, praziquantel insertion

\section{Introduction}

Many people around the world, including those in North America and European, have started to eat raw fish. Thus, the incidence of worm infections can be expected to increase. When infection occurs in early childhood, it is necessary to offer supportive care in addition to standard treatment with oral praziquantel or with insertion of a duodenal tube using a radiopaque contrast medium. Young patients are usually constipated or cannot evacuate feces intentionally and the invasive treatment is unfavorable for young patients. We have experienced a 2-year-old girl with Diphyllobothrium nihonkaiense infection treated with oral praziquantel and a laxative.

\section{Case Report}

A 2-year-old girl living in Tokyo was found to have a Cestoda infection and was referred to our hospital for deworming. She had recurrent abdominal pain and diarrhea and sometimes complained of a strange feeling at her anus. Her mother had once noticed a tape-like white substance hanging from her anus. Her grandfather was a fish dealer and lived together with the patient and her parents. The patient and her family often regularly consumed several species of raw fish, including Oncorhynchus keta and Oncorhynchus masou.

On admission, the patient was $94 \mathrm{~cm}$ tall and weighed $14 \mathrm{~kg}$; there were no abnormal findings on general examination. Blood tests showed no significant abnormalities: white blood cell count, 6,600 / $\mathrm{LL}$ (eosinophils 6.0\%; $396 / \mu \mathrm{L}$ ); hemoglobin, $13.1 \mathrm{~g} / \mathrm{dL}$; platelets, $18.8 \times 10^{4} / \mu \mathrm{L}$; and C-reactive protein, $0.1 \mathrm{mg} / \mathrm{dL}$. Results of liver function studies and urinalysis were normal. Other laboratory results included a Fe level of $111 \mu \mathrm{g} / \mathrm{dL}$ and a vitamin $\mathrm{B}_{12}$ level of $762 \mathrm{pg} / \mathrm{mL}$. On microscopic stool examination, round, light-yellow eggs, approximately

Correspondence to Atsushi Fujita, MD, Department of Pediatrics, Nippon Medical School, 1-1-5 Sendagi, Bunkyo-ku,

Tokyo 113-8603, Japan

E-mail: bx102761@nms.ac.jp

Journal Website (http://www.nms.ac.jp/jnms/) 


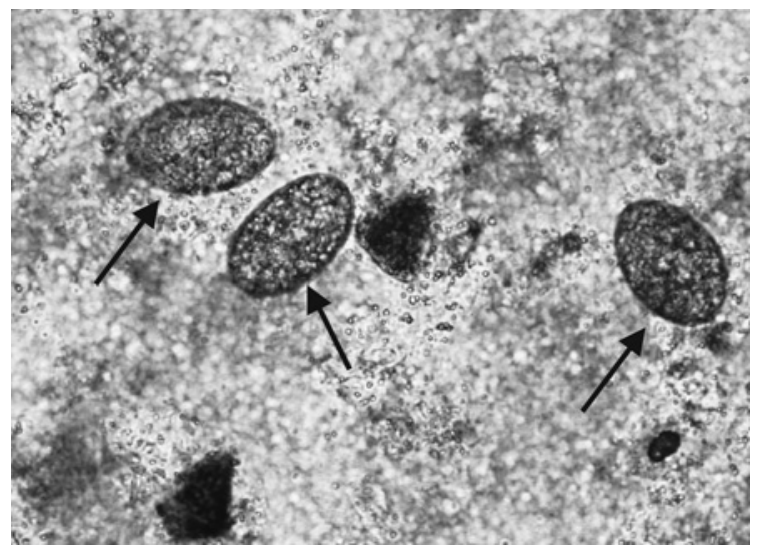

Fig. 1 On microscopic stool examination, round, light-yellow eggs, approximately $45 \times 45 \times$ $55 \mu \mathrm{m}$ in size, are seen.

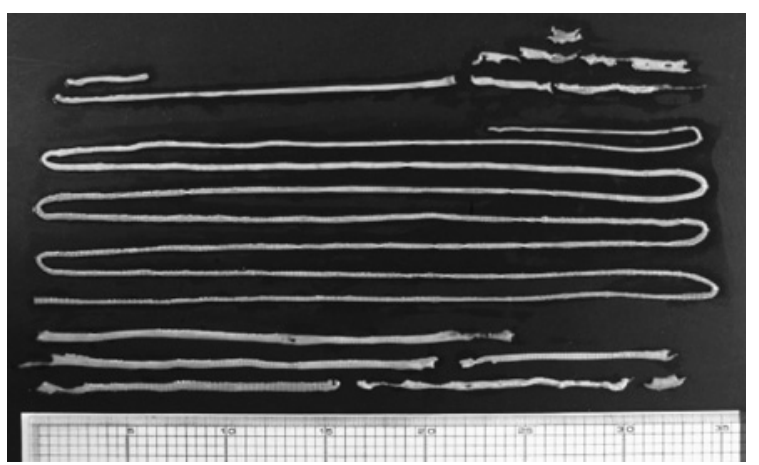

Fig. 2 The excreted $400 \mathrm{~cm}$ cestode had been digested into 7 pieces. The scolex was not found after the first treatment.
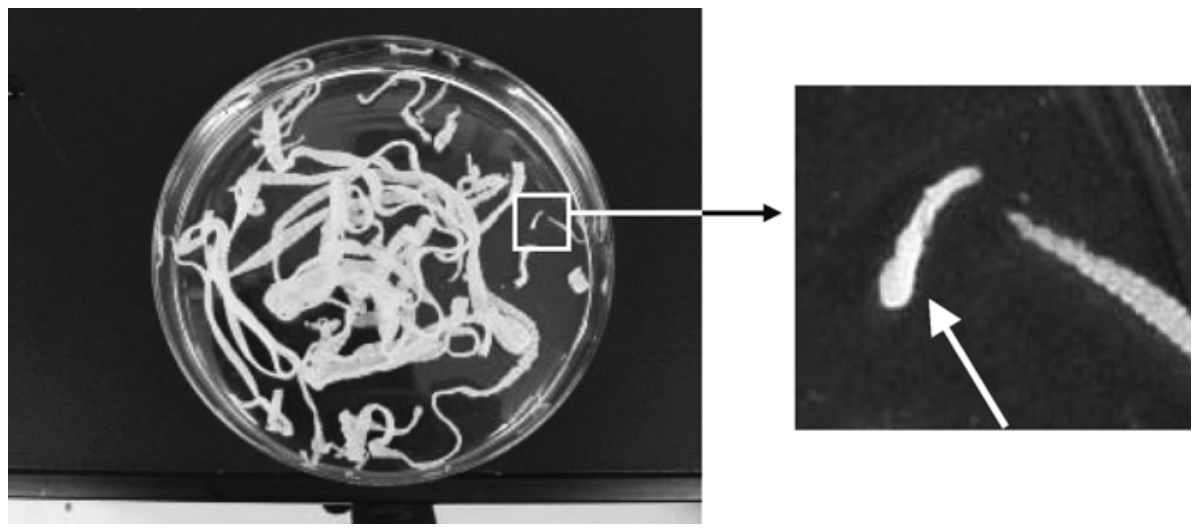

Fig. 3 The scolex was found with $300 \mathrm{~cm}$ of the cestode after the second treatment.

$45 \times 45 \times 55 \mu \mathrm{m}$ in size, were observed (Fig. 1). $D$. nihonkaiense infection was diagnosed on the basis of the tape-like white substance observed at the anus and of the eggs that were seen on stool examination. Even though no other family members had complaints, the father was found to have Metagonimus yokogawai infection on stool testing.

Because the insertion of a duodenal tube and the use of an oral radiopaque contrast medium (Gastrografin) seemed inappropriate in a 2-year-old girl, we administered oral praziquantel for deworming. On the first day, $10 \mathrm{mg} / \mathrm{kg}$ of praziquantel was given orally, followed 2 hours later by oral magnesium oxide to help evacuate the bowels and the worm. Unfortunately, the patient was usually constipated and had a bowel movement every 2 to 3 days. Although a bowel movement did not occur on the day that magnesium oxide was given, $400 \mathrm{~cm}$ of the cestode was evacuated, but the excreted body had been digested into 7 pieces, and the scolex could not be found (Fig. 2).

One month later, microscopic stool examination again revealed round eggs, and a second deworming treatment was carried out. On the first day, the same dose of oral praziquantel was given along with a $30 \mathrm{~mL}$ glycerin enema. Two hours later, oral magnesium oxide was given, and a second $30 \mathrm{~mL}$ enema was given. Nevertheless, the patient did not have a bowel movement that day. The next morning, a $30 \mathrm{~mL}$ glycerin enemas were given twice. After breakfast, the patient had a bowel movement, and $300 \mathrm{~cm}$ of the cestode was evacuated along with the scolex (Fig. 3). The patient's abdominal symptoms resolved, and 1 month later, stool examination was negative. 


\section{Discussion}

We have described a rare case of $D$. nihonkaiense infection in a 2-year-old Japanese girl. In recent years, eating habits have changed, and the Japanese style of eating raw fish as sushi or and has become popular in North America and Europe. Even in Japan, new types of fish, such as anchovy, sardine, Jack mackerel, and oncorhynchus, are being eaten as sushi and sashimi. Thus, the incidence of worm infection can be expected to increase. We have successfully performed deworming with oral praziquantel combined with a laxative and enemas.

The life cycle of $D$. nihonkaiense requires two intermediate hosts. First, eggs that are passed in the feces hatch into small ciliated coracidium larvae, which swim around until ingested by copepods, in which the growth of the second larval stage, the preceoid, is completed. The second host, O. masou, ingests the infected crustaceans, and the larvae continue to grow in the flesh of the fish. The fish are eaten by humans, who are the definitive hosts and in whom larvae grow to the adult stage ${ }^{1,2}$. The cestode grows to 5 to $10 \mathrm{~m}$ in length through the continuous proliferation of new strobilae (maximum, 3,000-4,000 strobilae) behind the scolex, which is required for the growth and survival of cestodes ${ }^{3}$. Therefore, it is important to confirm that the scolex is evacuated from the human body to assure complete cure of $D$. nihonkaiense infection ${ }^{4}$

The contrast medium Gastrografin has been shown to be useful for treating large $\operatorname{cestodes}^{5.6}$; the advantage of this method is that the deworming is confirmed by the discharge of a living worm with its scolex. However, to locate the worm, a patient is continuously exposed to X-rays. Furthermore, the insertion of a duodenal tube to administer the Gastrografin did not seem possible in our 2-year-old patient. The effectiveness of praziquantel for treating D. nihonkaiense has been reported ${ }^{4,7}$. Praziquantel digests the worm; thus, the scolex and the proximal segments sometimes become separated $^{4}$. It is necessary to confirm that the whole body, especially the scolex, has been excreted, because the worm can re-grow if the scolex is retained and survives. Various single oral doses of praziquantel ranging from 10 to $50 \mathrm{mg} / \mathrm{kg}$ have been suggested for the treatment of $D$. nihonkaiense infection ${ }^{8}$. Recently, the use of a single low dose (5$10 \mathrm{mg} / \mathrm{kg}$ ) of praziquantel was reported ${ }^{9}$. Our case shows that although the dose of praziquantel is an important issue, supportive care, including the optimal use of an oral laxative and enemas to ensure smooth evacuation of the worm, is also important. This is especially true for young patients who are usually constipated or who cannot evacuate feces intentionally.

\section{References}

1. Lynnes G, David B: Diagnostic Medical Parasitology. 3rd edn, 1997; pp 308-314, 568, ASM press, Washington.

2. Markell EK, Voge M, John DT: Medical Parasitology. 7 th edn, 1992; pp 226-230, WB Saunders, Philadelphia.

3. Yoshida Y, Arizono N: Illustrated Human Parasitology. 7th edn, 2006; pp 188-191, Nanzando, Tokyo (In Japanese).

4. Ohnishi K, Murata M: Treatment with praziquantel for human Diphyllobothrium nihonkaiense infections. Jpn J Parasitol 1993; 43 (suppl.): 106 (In Japanese).

5. Nakabayashi T, Ono T, Nakai T, et al.: A new therapy for Taenia saginata and Diphyllobothrium latum infection by duodenal administration of Gastrografin. Jpn J Parasitol 1984; 33: 215-220.

6. Waki K, Oi H, Takahashi S, Nakabayashi T, Kitani T: Successful treatment of Diphyllobothrium latum and Taenia saginata infection by intraduodenal 'Gastrografin' injection. Lancet 1986; 2: 1124-1126.

7. Yoneyama $\mathrm{T}$, Isobe $\mathrm{A}$, Ohnishi K: Morphological observations of Diphyllobothrium nihonkaiense treated by praziquantel. Jpn J Parasitol 1993; 42: 161 (In Japanese).

8. Kanamaru H, Hashimoto $\mathrm{K}$ : The cases of diphyllobothriasis and its managements. J Pediatr Practice 1996; 59: 2097-2100 (In Japanese).

9. Ohnishi K, Kato Y: Single low-dose treatment with praziquantel for Diphyllobothrium nihonkaiense infections. Intern Med 2003; 42: 41-43.

(Received, March 7, 2008)

(Accepted, April 18, 2008) 